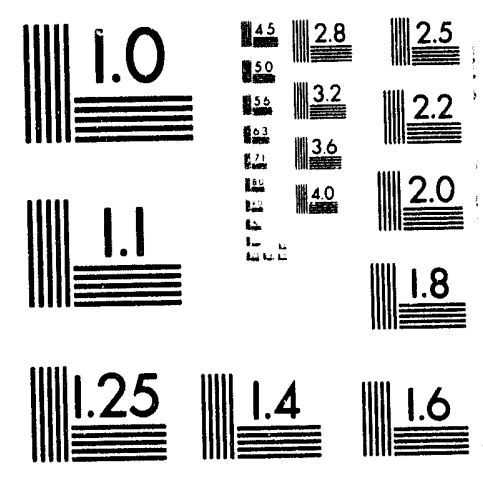




$$
\overrightarrow{\mathrm{o}}
$$




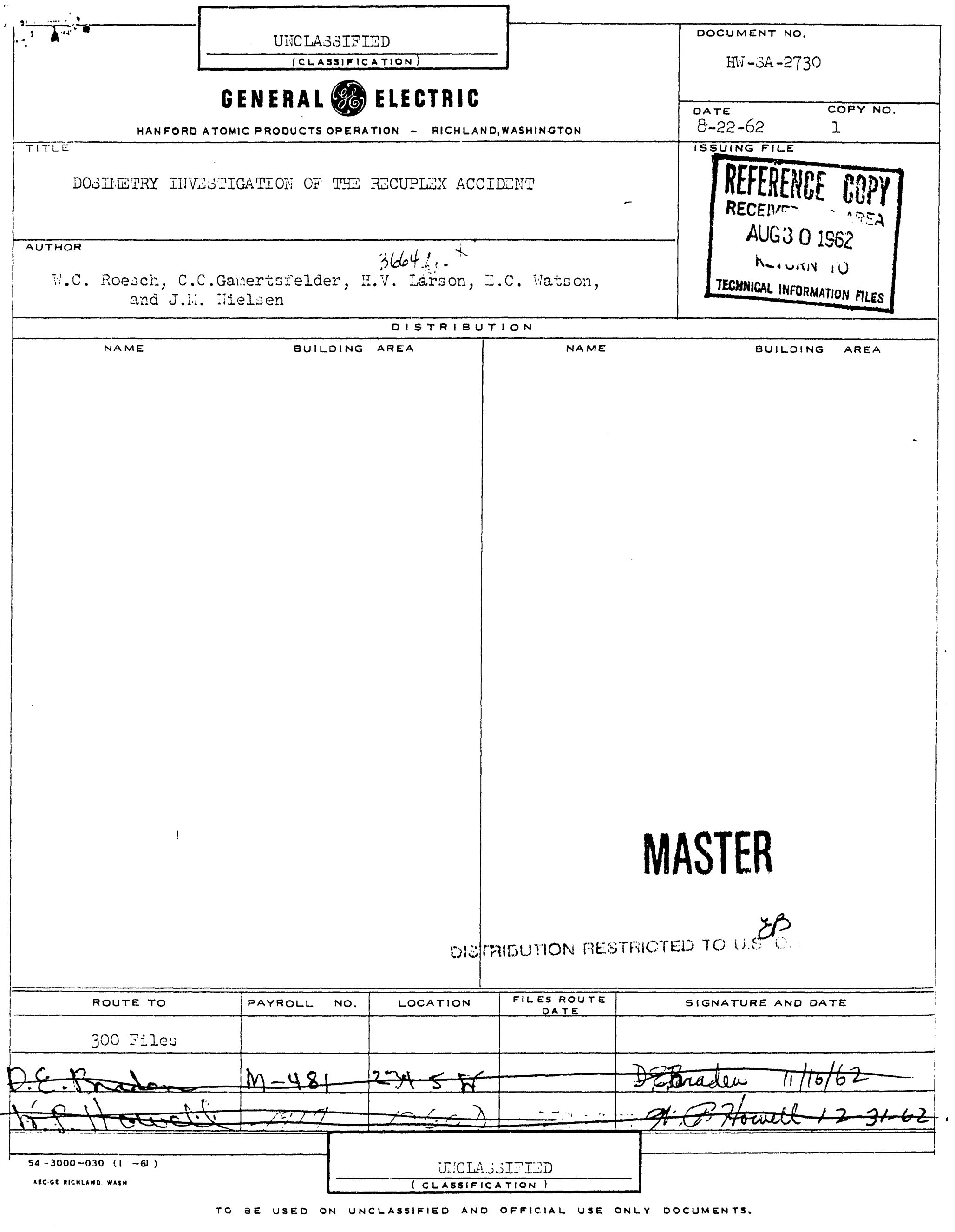


DOSIMETRY INVESTIGATION OF THE

RECUPIEX CRITICALITY ACCIDENT

\author{
Hanford Iaboratories* \\ General Electric Company \\ Richland, Washington
}

\title{
INTRODUCTION
}

At 10:59 AM (PST), Seturday, April 7, 1962 a criticality accident occurred in a plutonium waste chemical recovery facility at the Hanford Atomic Proaucts Operation, operated for the Atomic Energy Comission by the General Electric Company. Four men were hospitalized but were released after medical observation and after estimates of the radiation doses received were available. Th1s report describes the dosimetry investigation that was made following the accident. This investigation was facilitated by the ract that all employees affected had personnel dosimeters in their possession when the incident occurred. The interpretation of the data supplied by these dosimeters was supplemented by information gathered by techniques that were developed in connection with other accidents. Below, the available information is first presented and then applied in a discussion of the dosimetry of the people involved in the accident.

\section{DESCRIPTION OF THE ACCIDENT}

The accident occurred in a facility known as Recuplex within a builiing known as the 234-5 Building. When the accident occurred, there were twentytwo persons in the 234-5 Bullding. The criticality alarm siren started almost at once (several people reported that air-proportional alpha contamination monitors broke down slightly before the siren sounded). All persons

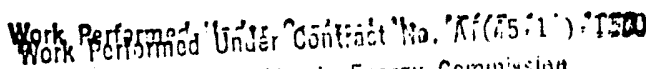

Between The Atomic Energy Ccminision

* This report was prepared by a committee consisting of C. C. Gamertsfelder,
H. V. Larson, J. M. Nielsen, W. C. Roesch (Chairman), and E. C. Watson. It H. V. Larson, J. M. Nielsen, W. C. Roesch (Chairman), and E. C. Watson. It reports the work of a number of people at Hanford. 
in the 234-5 Building evacuated to a gate house (2701-Z) about a hundred yards Irom $234-5$ and then took shelter behind another building (2704-Z) when the former area was found to have an exposure rate of about $200 \mathrm{mr} / \mathrm{hour}$. Within five to ten minutes they had evacuated these areas in the evacuation bus or by private car. Two patrolmen, stationed in the gate house at the time of the excursion, increased the total number of evacuees to twenty-four.

The evacuees went to the first aid building for the area (except for one who went to the area badge house and was directed to first aid). By this time the employees who had been in the Recuplex area and had seen the Cerenkov radiation flash were known; however, all employees were given a "Quick Sort" examination to determine who had been exposed to significant fast neutron doses $^{1)}$. The counting rate of a Geiger counter held at their abdomen was observed while the person bent over around the counter. Only those employees who had been in the Recuplex area gave significant readings.

Contamination surveys of the evacuees were also made while they were at the first aid building. No contamination was found. Their personnel dosimeters were collected for examination. Personal effects were examined for radioactivity and then sent in for laboratory study. The first blood and hair samples and excreta collections were made.

After examination and treatment at Kadlec Hospital, four persons, including the three most highly exposed, were sent to the Hanford Whole Body Counter for examination. The next day all but one of the remaining evacuees were also examined at the Counter; the last man was examined the following day. Whole body counts and blood and excreta collection were repeated on the most highly exposed persons until no radioactivity of interest was detectable. 
Information was obtained immediately from each employee to establish where he had been when the criticality alarm sounded and how he left the building. Detailed personal interviews were made during the following week. AlI but five people in the 234-5 Building evacuated immediately upon hearing the siren; all but one had left within about two minutes; the last man was out within four minutes. The routes each one followed in leaving the building are shown in Figures 1 and 2 .

Information for the three most highly exposed persons was made as detailed as their recollections would allow. Figure 3 shows where these people were standing at the time they saw the Cerenkov radiation flash. Employee \#I was standing immediately below the critical vessel, the $\mathrm{K}-9$ Tank, manipulating a valve at the face of the hood containing the tank. His body was very close to the hood wall. His eyes were about 5 feet from the center of the K-9 Tank; the parts of the trunk of his body were between 6 and 8 feet away. Employee \#17 was standing about 2 feet to the side and about 5 feet behind Employee \#1. There was a movable lead shield behind \#I, but \#I7 was in full view of \#I and of the K-9 Tank. \#l7's eyes were about 10 feet from the center of $\mathrm{K}-9$ and the trunk of his body was 10 to 11 feet away. The K-9 Tank is cylindrical with a capacity of 69 liters; it contained about 45 liters when the excursion occurred. The tank has a Pyrex wall about $3 / 8$ inch thick and a steel bottom plate about one inch thick. \#1 and \#17 were exposed to radiations coming through both the wall and the bottom. The only other materials between them and the tank were the half inch thick lucite hood walls and some plumbing inside the hood. Employee \#23 was standing in front of another hood about 26 feet from the center of $\mathrm{K}-9$. Most of the radiation reaching him probably came through the sides of the tank. The only materials between him and $K-9$ were the lucite walls of 


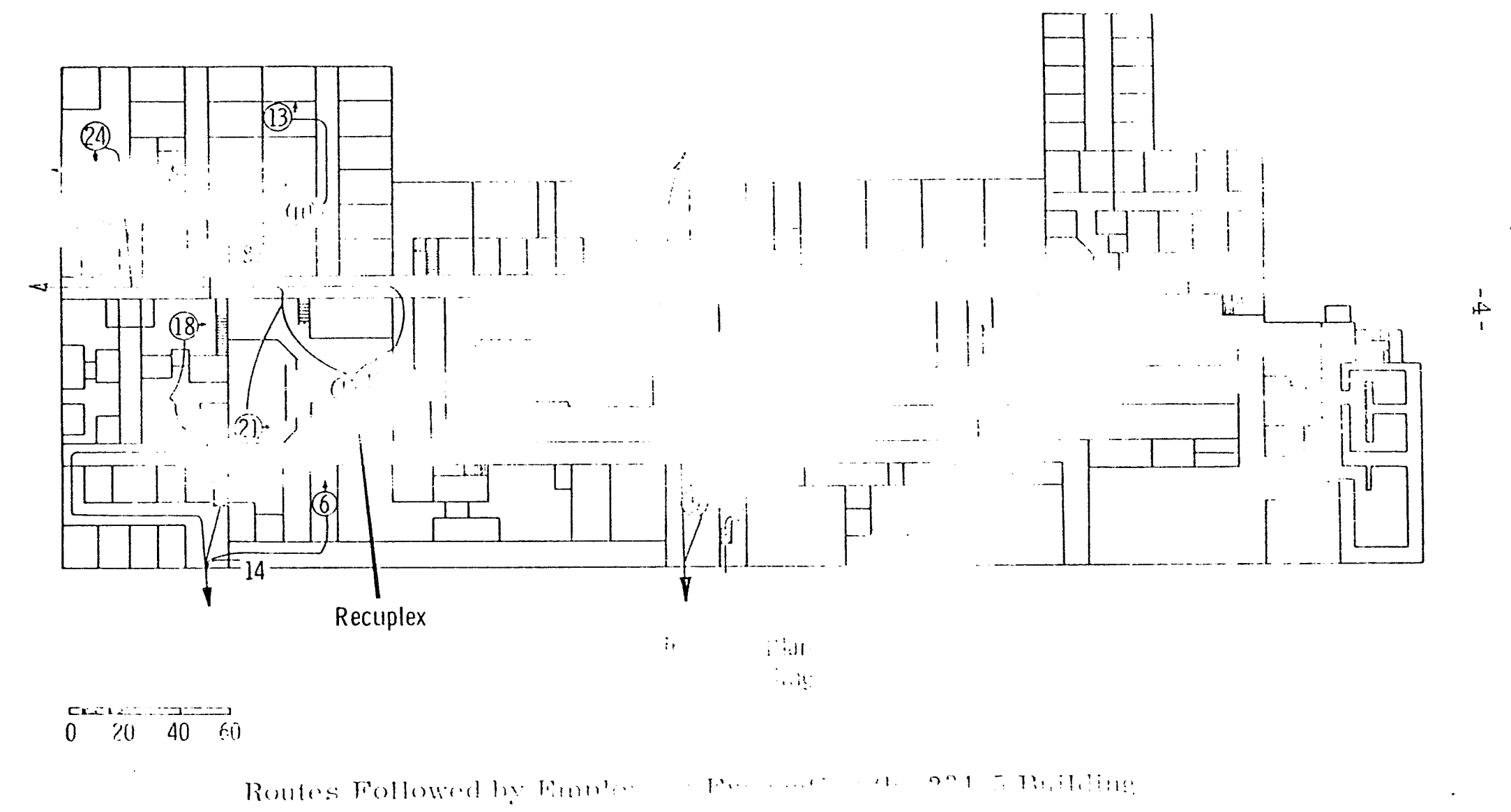




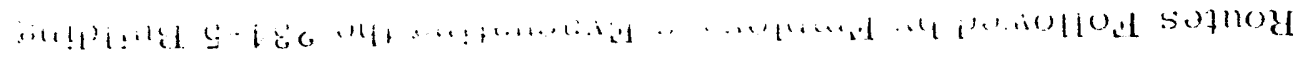

$$
\text { 1.: : : }
$$

\section{Gu!pl!ng s-DEZ}

Ueld tolly pU0.0\%

\section{UV UC I)}

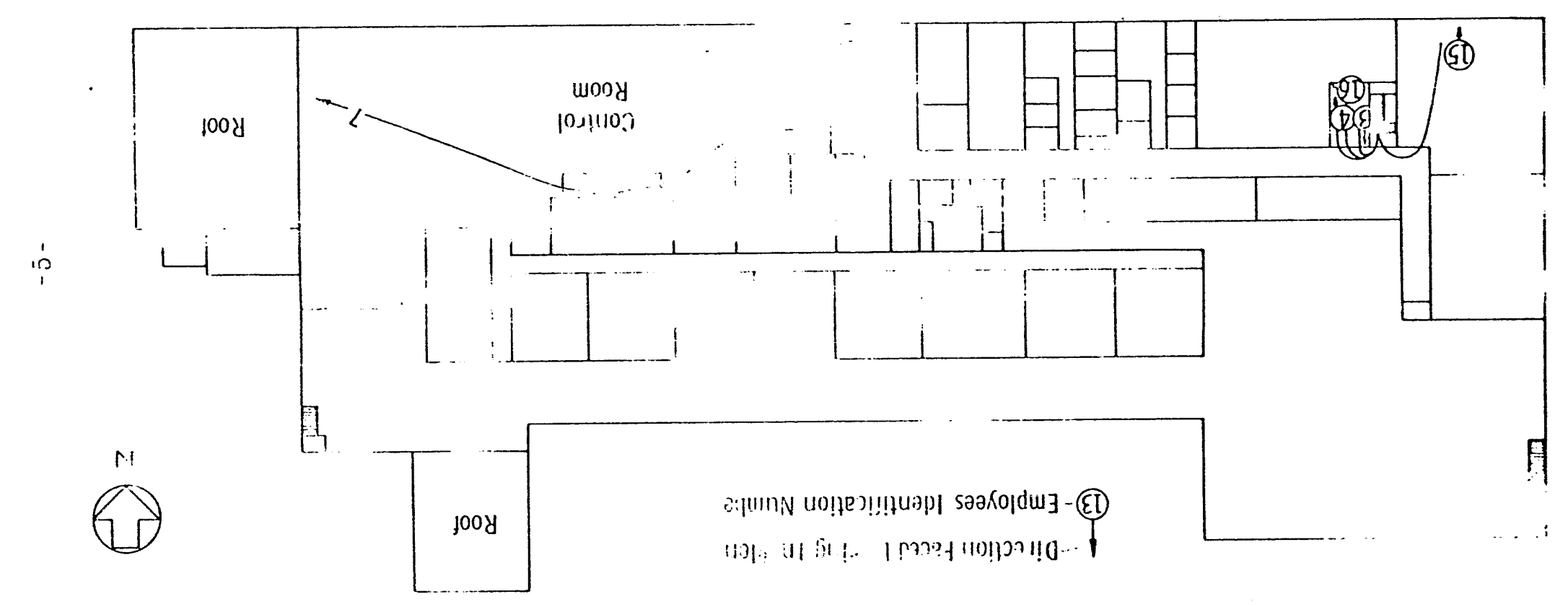




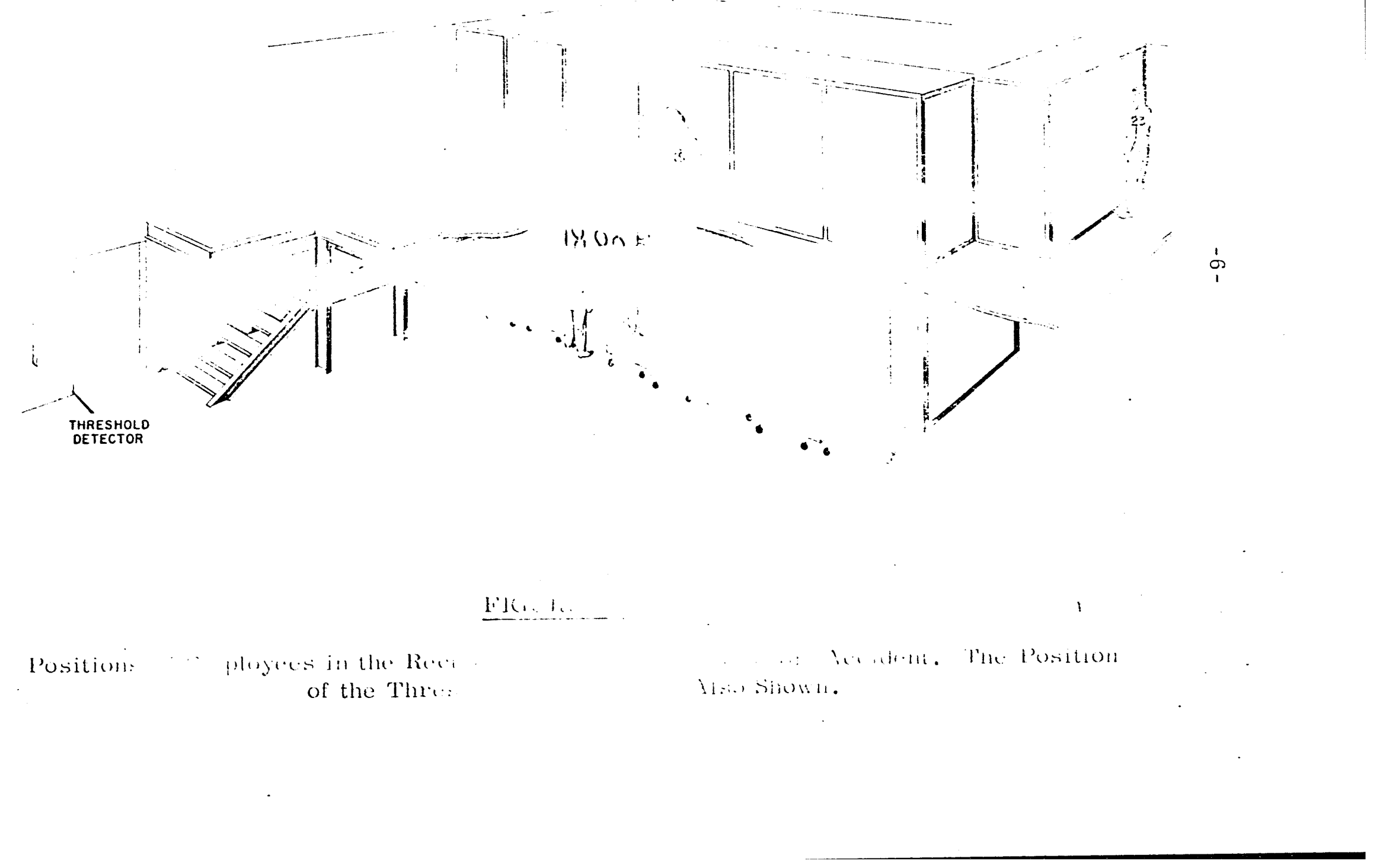


the hood containing $K-9$ and the hood he was facing and the thin metal back of the latter.

Of the next two most highly exposed people,- Employee \#6 was about 30 Peet from K-9 with one concrete wall about 4 inches thick and one metal partition wall in between. This employee delayed to lock up some classified documents but was outside the building in about 25 seconds. Employee \#2l was about 40 feet away and was shielded by an 8 inch thick concrete wall.

Before considering the measurements made for each individual, information of general interest can be obtained from instruments that were near the scene of the accident. Two recording $\mathrm{BF}_{3}$ counters (one for high levels, one for low) were operating at the time of the accident in an incinerator room in the 234-5 Building. The data from the chart recorders are plotted in Figure 4. They indicate an initial excursion the exact magnitude of which cannot be determined because the flux level is recorded only every 30 seconds and it may be expected to vary by orders of magnitude within such a time period. Following this initial pulse which presumably activated the criticality alarm there was a continuing nuclear reaction of a magnitude sufficlent to keep the recorder off-scale for a period of about 30 minutes. After the recorder returned to on-scale readings the fissioning continued at a generally reduced rate till 36 hours after the incident began. It appears that those in a position to be most seriously exposed to the critical vessel evacuated in time to limit their exposure to only a part or all of the initial excursion.

A threshold detector ${ }^{2)}$ was located about 26 feet from the critical vessel. Its position is shown in Figure 3. At least one of the steel beams of the stairway shown in the figure was on the line-of-sight between the 
$-8-$

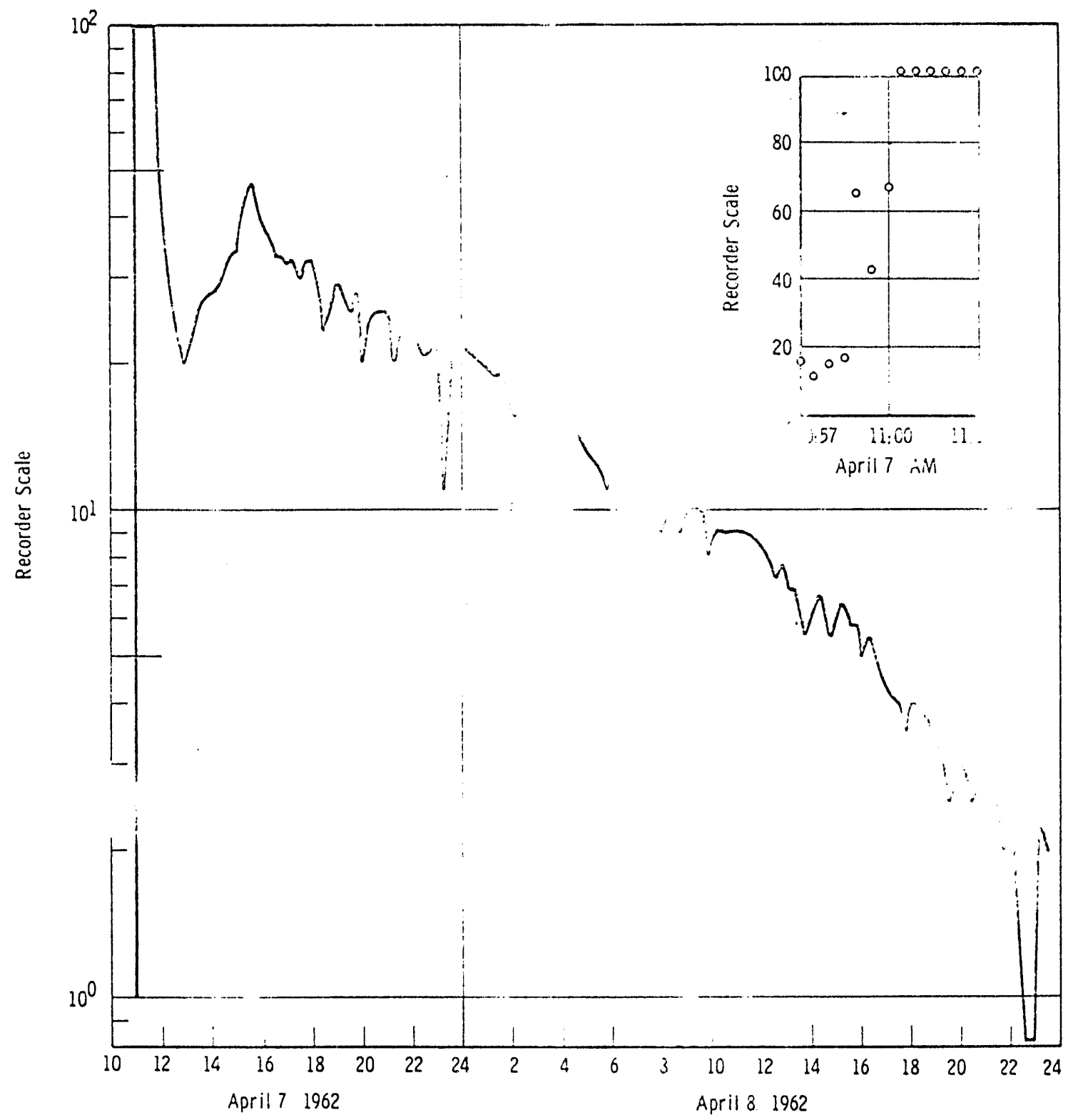

FIGTRE 4

Da.: irom a Recording $\mathrm{BF}_{3}$ Counter Operating in the $234-\bar{j}$ Building at $\mathrm{t}$ Time of the Accident. 
vessel and the dosimeter. The metal grid floor of the mezzanine level, the stairway, and another hood at the head of the stairs provided masses of material in which radiation from $K-9$ could scatter and then reach the detector. These certainly influenced the relative spectra of the neutrons reaching the detector as compared to those reaching the men. For lack of other information, however, the spectrum received by the detector was used in analyzing other pertinent data. The detector was removed about 96 minutes after the accidental excursions started so it was present during the large excursion shown in Figure 4 as well as during the time the people were present.

The results obtained from analysis of the threshold detector are given in Table I. The results relative to the neutrons $/ \mathrm{cm}^{2}$ measured with the plutonium foil are also given. The latter is. assumed to include all the neutrons above $1 \mathrm{Kev}$.

\section{TABLE I}

Threshold Detector Results

\begin{tabular}{llll}
$\begin{array}{c}\text { Neutron } \\
\text { Energy Band }\end{array}$ & \multicolumn{1}{c}{$\mathrm{n} / \mathrm{cm}^{2}$} & $\begin{array}{c}\text { Relative* } \\
\mathrm{n} / \mathrm{cm}^{2}\end{array}$ & $\begin{array}{l}\text { Relative* } \\
\text { Dose }\end{array}$ \\
Thermal & $1.17 \times 10^{10}$ & 0.39 & 0.005 \\
$1--750 \mathrm{Kev}$ & $1.26 \times 10^{10}$ & 0.42 & 0.25 \\
$0.75--1.5 \mathrm{Mev}$ & $1.05 \times 10^{10}$ & 0.35 & 0.40 \\
$1.5--2.5 \mathrm{Mev}$ & $0.34 \times 10^{10}$ & 0.11 & 0.15 \\
$>2.5 \mathrm{Mev}$ & $0.35 \times 10^{10}$ & 0.12 & 0.20
\end{tabular}

*Relative to $\mathrm{n} / \mathrm{cm}^{2}$ or to dose for neutrons above $1 \mathrm{Kev}$.

The number spectrum is presented in Figure 5. For comparison several other spectra obtained with threshold detectors 3$) 4$ 5) and normalized in the same way are shown in Figure 6. Figure 7 shows histograms prepared from calculated spectra 6); since information is lost in going from the calculated spectra to 
-1 ;

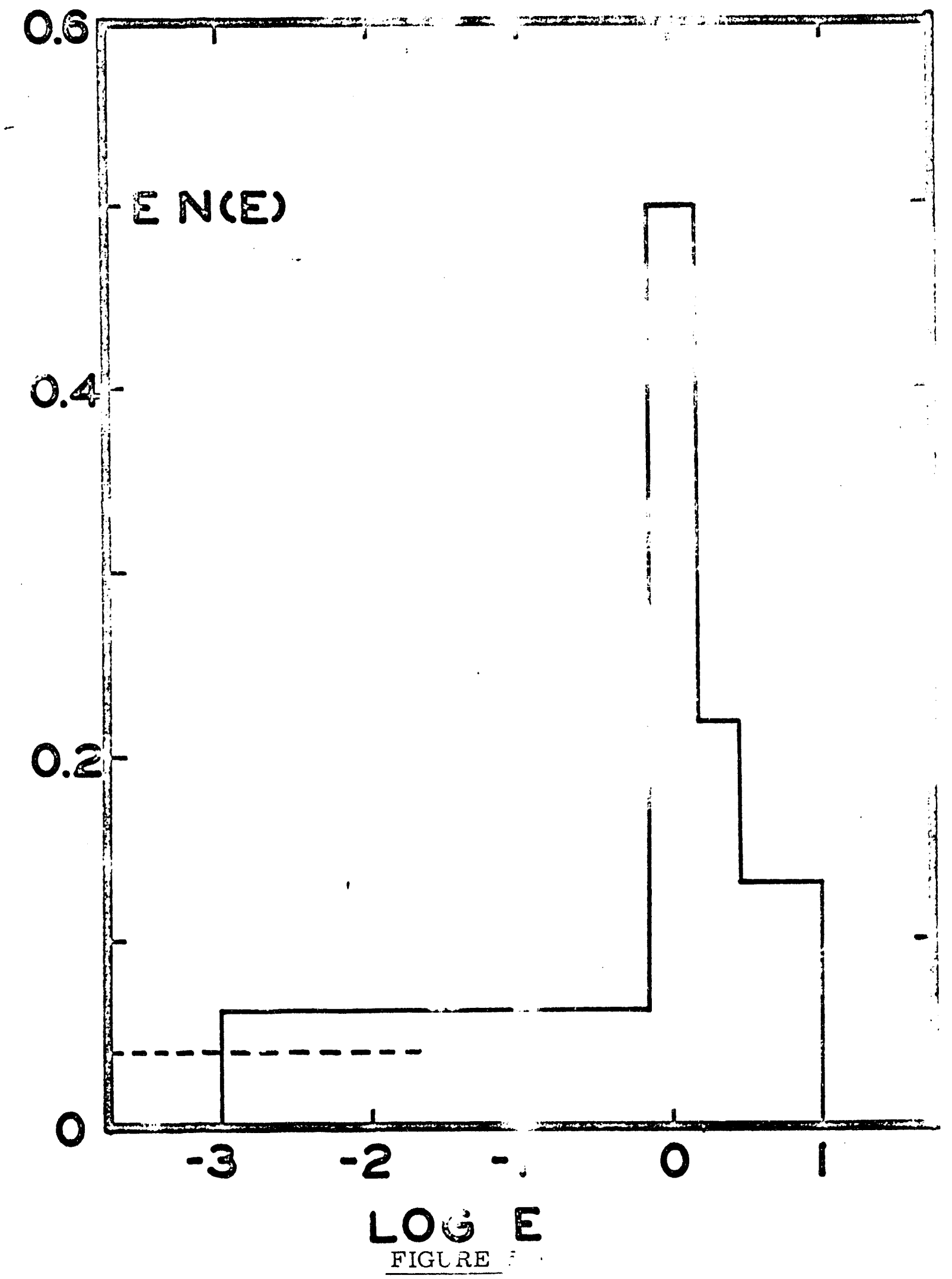

"pectrum $: \%$, red with Threshold Dei. During Recuplex Alcident. 
$-11-$

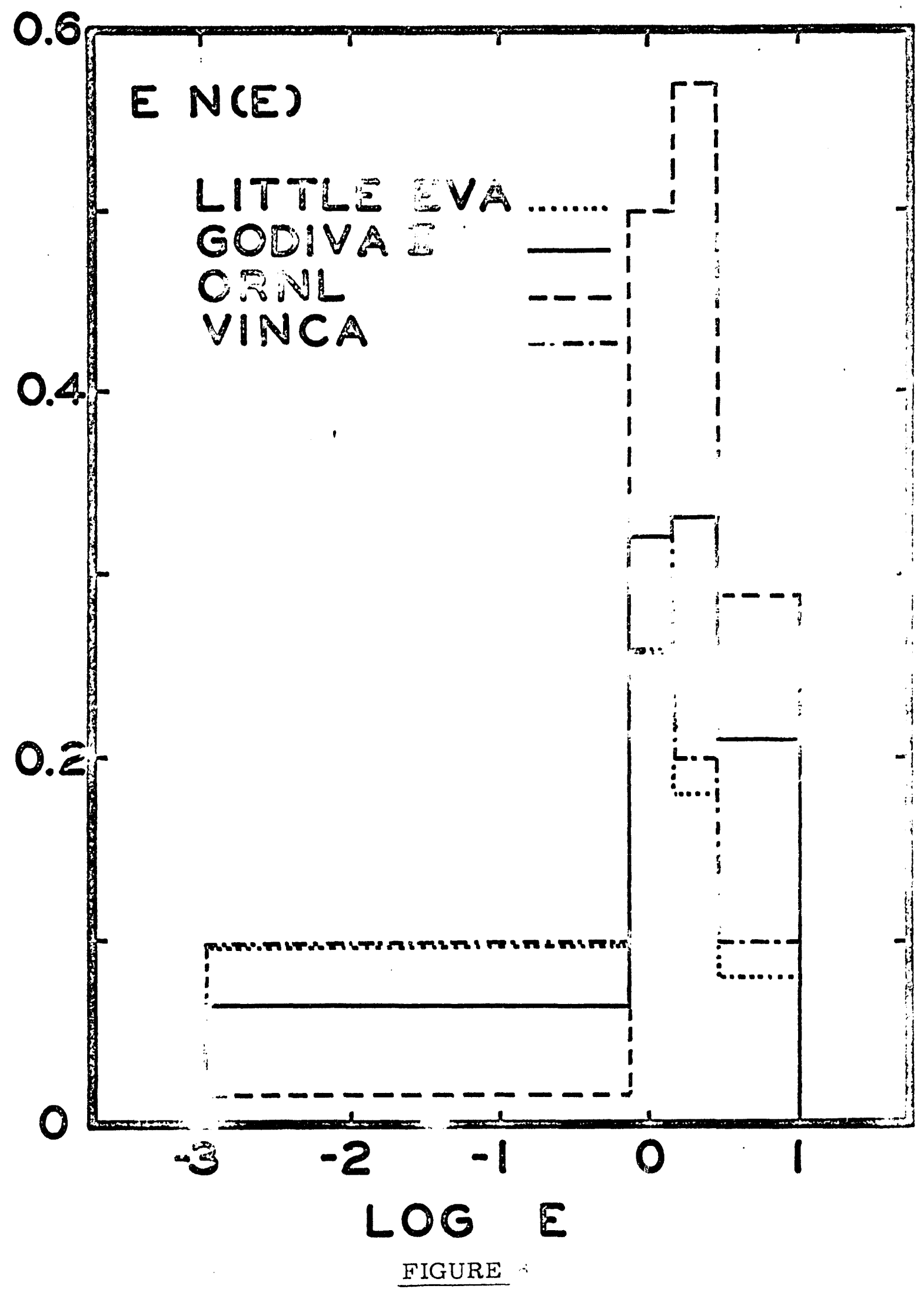

Experimental Spectra Teasured with Thr. 


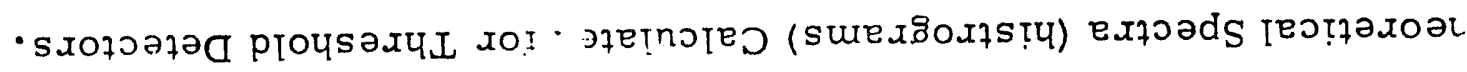

$$
3 \quad 507
$$
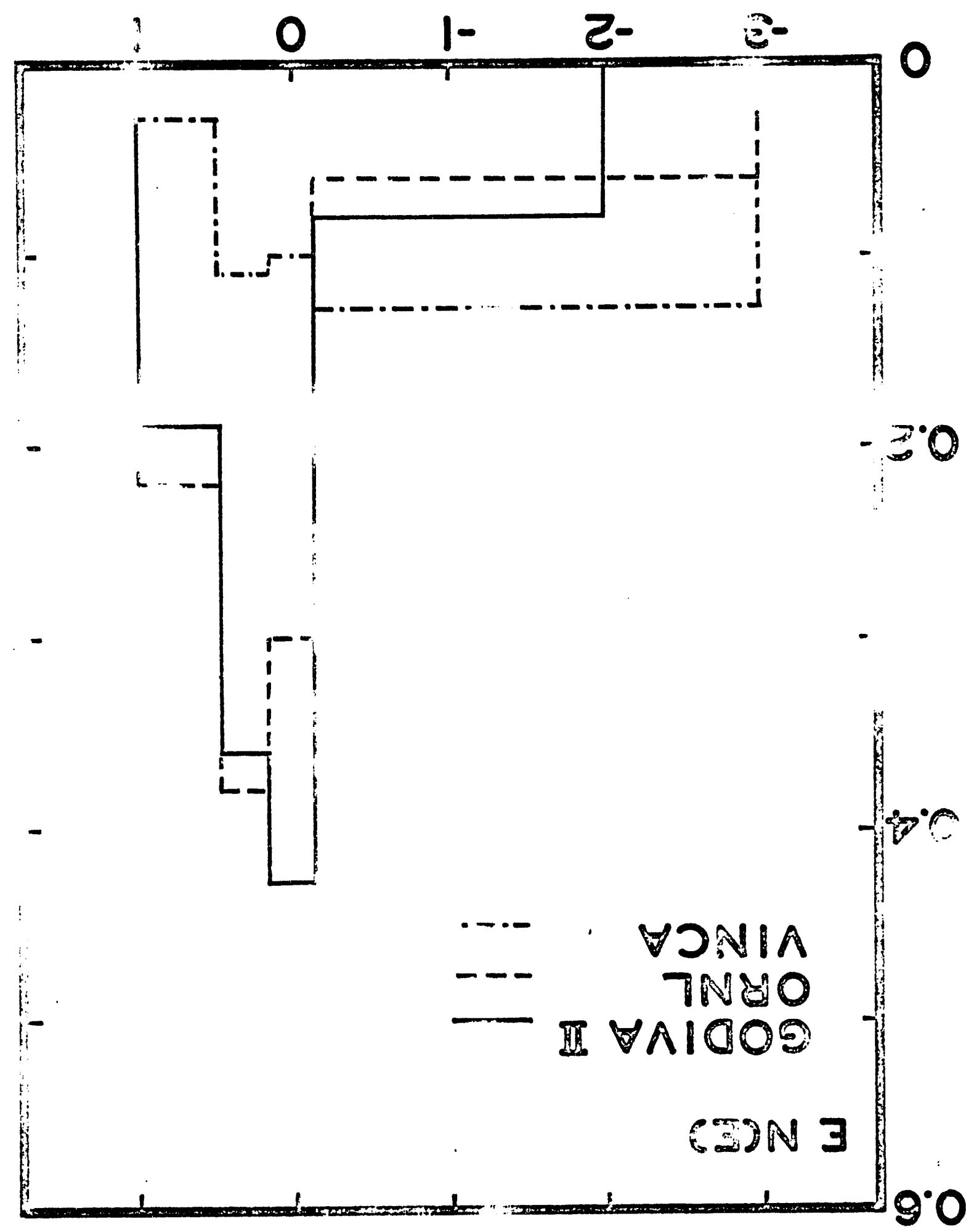
the histograms, the original normalized spectra are given in Figure 8. There is not close agreement between the present spectrum and any of the others, but the general features are the same and the differences are of the sort to be expected if the present results include the effects of a significant number of scattered, and hence lower energy, neutrons. Table I also contains the dose spectrum normalized to unit dose for the neutrons above $1 \mathrm{KeV}$.

The threshold detector was calibrated and interpreted in a slightly different manner ${ }^{7)}$ from that described in the original reference ${ }^{2)}$. The calibration constant provided for the sulfur disk in reference 7 was increased by a factor $1.5=0.34 / 0.23$. The 0.34 is the cross section in barns of the $S(n, p)$ reaction at $4.2 \mathrm{Mev}$, the energy used in the calibration. The 0.23 is the effective cross section in barns for neutrons above 2.5 Mev for spectra similar in shape to fission spectra above this energy. The intermediate neutron energy spectrum was estimated from the activation in the gold and cadmium-covered gold foils in the detector. If $\phi_{\text {th }}$ was the thermal neutrons $/ \mathrm{cm}^{2}$ and if $\sigma_{2200}$ is the activation cross section of gold for neutrons whose velocity is $2200 \mathrm{~m} / \mathrm{sec}$, then the difference in activity of the two foils is proportional to $\frac{1}{2} \sqrt{\pi} \sigma_{2200} \phi_{t h}$. If the intermediate neutron flux is assumed to be given by $\mathrm{k} \phi_{\mathrm{Pu}} / \mathrm{E}$, where $\mathrm{E}$ is the neutron energy, $\mathrm{k}$ is a constant, and $\phi_{\mathrm{Pu}}$ the flux measured by the shielded plutonium foil, then the activation of the cadmium covered foil is proportional to

$$
k \phi_{\mathrm{Pu}} \int \sigma_{\mathrm{act}}(\mathrm{dE} / \mathrm{E})
$$

where the integral is over the activation cross section of gold. Measured foll activities of 1.6 and $1.0 \times 10^{6}$ disintegrations/min, Hughes ${ }^{8)}$ values of the cross sections, and flux ratios from Table I give $k=0.042$. This is shown as a dashed line in Figure 5 and is in good agreement with the spectrum determined with the threshold foils. 


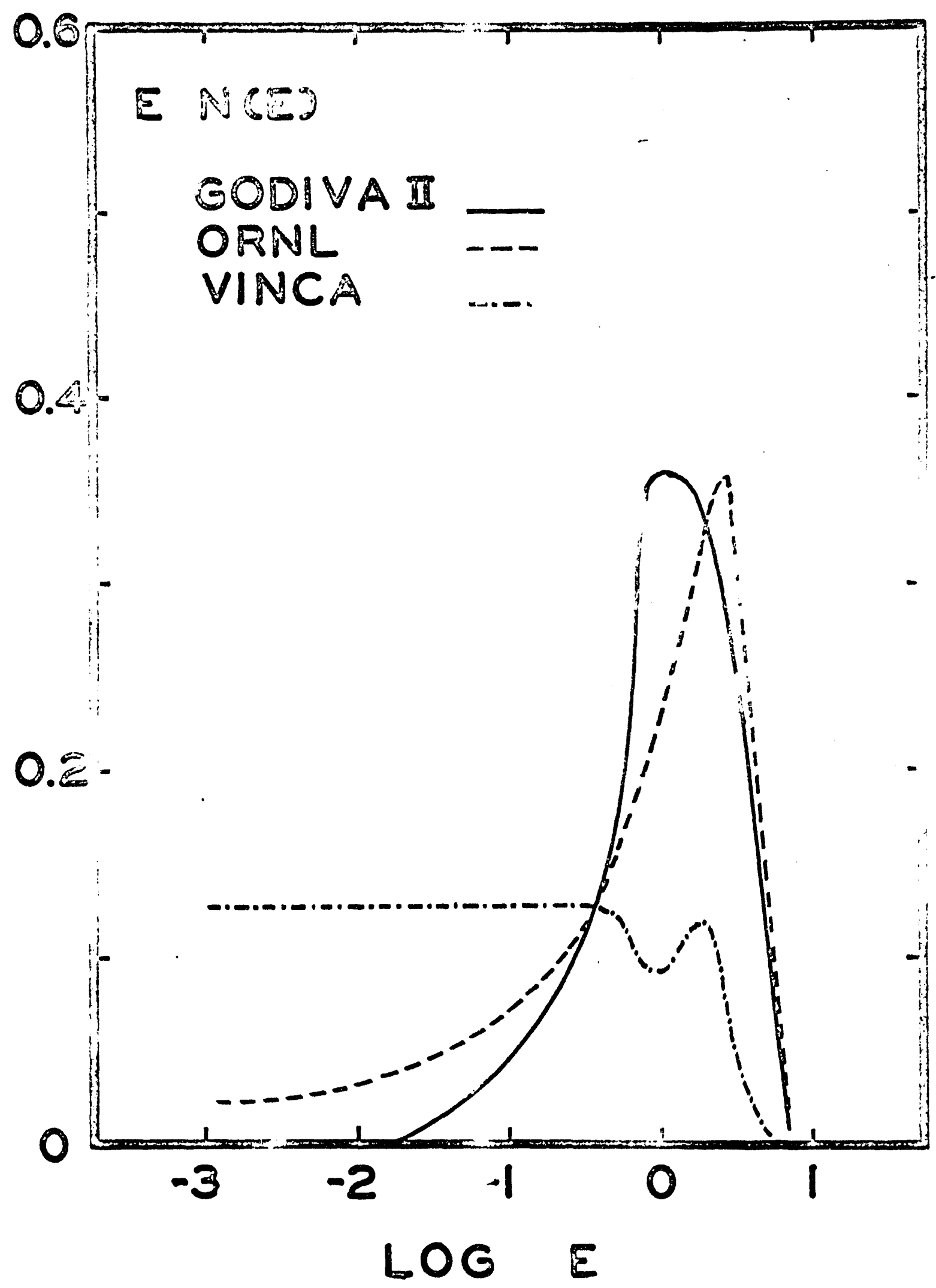

\section{FIGURE 8}

$T$. retical Spectra from Which the Histrograms Were Prepared. 
PERSONNEL DOSIMETERS

Each of the persons near the critical vessel* at the time of the accident was wearing his Hanford Film Badge Dosimeter ${ }^{9)}$. The dosimeters had last been exchanged 15 days before the accident; therefore, particularly for the smaller doses, a significant part of the darkening of the film may have been produced during employment prior to the accident.

The exposures of Employees \#1, \#17, and \#23 were so great that the developed sensitive (508) film from their dosimeters was too dark to permit optical density measurements. The insensitive (1290) film from their dosimeters was used to obtain their doses. Because of slow neutron activation of the aluminum and silver absorbers in the dosimeters, there was additional darkening of the areas of the dosimeter covered by them so the usual interpretation methods could not be used. The doses were determined from the densities of the unshielded portion of the dosimeter (the open window). There is an uncertainty in doing this ${ }^{10}$ ) because during both exposure and calibration the film is affected by secondary electrons produced by the photons in the environment of the dosimeter as well as in the material of the dosimeter itself. In the present case the dose determined from the open window could have been as much as 15 percent too low because of this effect. The dosimeter contains a lead strip in which the payroll number and other information is punched. For the films in question there was enough unused area under the lead tape to take a densitometer reading. These readings were compared with similar readings on the calibration films; they gave dose estimates that confirmed those from the open window readings. In making this comparison it is assumed that there is no appreciable slow neutron *Two patrolmen stationed in the gate house received negligible doses and are not considered further in this report. 
activation of the lead tapes and no effect due to different photon spectra.

Some of the darkening of these films must have been due to neutron activation of the materials in the emulsion. It has been reported ${ }^{11}$ ) that 0.13 rad of thermal neutrons or about 40 rads of fast neutrons (first colI1sion dose) would produce the same darkening of $129011 \mathrm{~lm}$ as $1 \mathrm{r}$ of Co-60 gamma rays. For example, if the exposure of Employee \#1 was 25 rads of fast neutrons plus 0.5 rad of thermal neutrons, the darkening predicted would be equivalent to $4.5 \mathrm{r}$ of gamma radiation. This is 7 per cent of the dose measured as described above.

The dosimeters of the other people in the 234-5 Bullding were, where necessary, read by these same methods but with the $508 \mathrm{film}$. The results of all the film badge dosimeter measurements are given in Table II. No corrections have been made for the neutron darkening just mentioned.

\section{TABLE II}

\section{Personnel Dosimeter Results}

(AII Exposures in Roentgens)

\begin{tabular}{|c|c|c|c|c|}
\hline Employee & $\begin{array}{l}508 \\
\text { F11m }\end{array}$ & $\begin{array}{l}1290 \\
\text { F11m }\end{array}$ & $\begin{array}{l}\text { Neutron } \\
\text { F1Im }\end{array}$ & $\begin{array}{c}\text { Finger } \\
\text { Ring }\end{array}$ \\
\hline 1 & & 63 & & 80 \\
\hline
\end{tabular}

0.03

0.12

0.15

0.02

0.98

0.04

0.10

0.05

0.06

0.07

0.20

0.13

0.70

0.20

$16 \quad 0.1$

$18 \quad 0.40$

$21 \quad 1.0$

$22 \quad 0.05$

$\begin{array}{ll}23 & 0.02\end{array}$ 
Employees \#21 and \#23 were wearing neutron film badge dosimeters ${ }^{12)}$. In each case the nuclear track plate was so darkened by the photon exposure that recoil tracks could not be identified. In the case of \#23, approximate readings of the $508 \mathrm{film}$ in the dosimeter could be made. They indicate a gamma ray dose of about $10 \mathrm{r}$, in agreement with h1s regular dosimeter, and about $3.5 \times 10^{9}$ neutrons $/ \mathrm{cm}^{2}$ of thermal neutrons.

Employees \#I and \#23 were wearing film ring dosimeters. These Indicated doses of 80 and $5.7 \mathrm{r}$, respectively.

Two additional studies were made with the personnel dosimeters of Employees \#1, \#17, and \#23. The very dark 508 f1lms were exposed to slow neutrons and measurements of the activation of the developed silver used as a measurement of the gamma ray dose recelved 13)14). The activation of the films was done in the large moderator used for producing slow neutron fluxes with the van de Graaf accelerator ${ }^{15)}$. The radioactivity was easily measurable ${ }^{16)}$, but it was found that the three films were at or very near the first maximum of the curve of activity versus dose for the calibration film 17 ). It was not possible to get accurate dose estimates. The same slow neutron facility was used to estimate the neutron flux that had produced the excess darkening on the 1290 film behind the silver shields. Fresh f1lms were exposed to gamma ray doses in the range of those to which the people were exposed and then exposed to slow neutrons until the total flux producing the same density pattern as on the personnel film was found. The neutron fluxes found in this way were decreased by a factor 0.79 to allow for the fact that part of the activation during the accident was due to intermediate energy neutrons. The factor was calculated from the gold foil activities in the threshold detector and the thermal neutron cross sections 
and resonance integrals of gold and silver ${ }^{8)}$. The thermal neutron fields estimated by this method are given in Table III.

\section{TABLE III}

Thermal Neutron Estimates From Film Badges

$\begin{array}{llc}\text { Employee } & \begin{array}{c}\text { Thermal } \\ \text { Neutrons } / \mathrm{cm}^{2}\end{array} & \begin{array}{c}\text { Estimated } \\ \text { Uncertainty }\end{array} \\ \# 1 & 2.3 \times 10^{10} & 10 \% \\ \# 17 & 6.5 \times 10^{9} & 50 \% \\ \# 23 & 3.1 \times 10^{9} & 200 \%\end{array}$

WHOIE BODY COUNTING

The occupants of the 234-5 Building at the time of the accident were counted in the Hanford Whole Body Counter ${ }^{18)}$. The measured values of $\mathrm{Na}-24$ activity, corrected for decay since the time of the accident, and the Individual's weights are given in Table IV. No correction was made for $\mathrm{Na}-24$ that might have been eliminated before the counting took place; it is estimated that only a few percent was missed in this way for those counted immediately. The quotient of the number of microcuries by the body weight in kilograms was multiplied by $215 \mathrm{rad}-\mathrm{kg} / \mu \mathrm{c}$ to obtain the first collision dose to the person.

The factor $215 \mathrm{rad}-\mathrm{kg} / \mu \mathrm{c}$ was obtained by averaging the following two experimental values. Measurements ${ }^{19)}$ with a burro at the mock-up of the Oak Ridge criticality accident gave $204 \mathrm{rad}-\mathrm{kg} / \mu \mathrm{c}$. An experiment with solutions of sodium salts in bottles at the Godiva II reactor gave 226 $\mathrm{rad}-\mathrm{kg} / \mu \mathrm{c}^{20)}$. 
Recently the dosimetry investigation of the Vinca critical accident was reported ${ }^{5)}$ for which an average factor of $81 \mathrm{rad}-\mathrm{kg} / \mu \mathrm{c}$ was used (neglecting corrections for the weights of the individual persons). The difference between this figure and those above is due to the presence of a very large proportion of thermal neutrons near the Vinca reactor. If the threshold detector measurements reported for that reactor and those reported above for the present criticality accident are used to estimate the neutron first collision dose per unit $\mathrm{Na}-24$ activation ${ }^{21}$, the rad-kg/uc factor for the Hanford accident is about 2.3 times that for the Vinca, i.e., about $190 \mathrm{rad}-\mathrm{kg} / \mathrm{\mu c}$. This is satisfactorily close to the value used above. Although, as remarked above, the threshold detector measurements for the Hanford accident probably represent a different spectrum than that to which the employees were exposed because of attenuation and scattering, the comparison of the Vinca and Hanford spectra to estimate the above factor is not much affected by the difference.

It is estimated that the Na-24 burdens were determined to an accuracy of about 5. percent where counting data were not limited by statistics. Counting statistics became important for burdens of about $0.001 \mu \mathrm{c}$ (before correction for decay). Those employees in whom less than $0.001 \mu \mathrm{c}$ was detected were assigned a dose of less than $0.01 \mathrm{rad}$. 


\section{TABLE IV}

Whole Body Counting Results

\begin{tabular}{cccc} 
Employee & Kc Na-24 & $\begin{array}{c}\text { Weight } \\
\mathrm{kg}\end{array}$ & $\begin{array}{c}\text { Neutron } \\
\text { First Collision } \\
\text { Dose--rads }\end{array}$ \\
\cline { 3 - 4 }$\# 1$ & 7.55 & 70.4 & 23 \\
2 & 0.001 & 85.3 & $<0.01$ \\
3 & 0.014 & 71.8 & 0.04 \\
4 & 0.022 & 95.4 & 0.05 \\
5 & 0.001 & 93.4 & $<0.01$ \\
6 & 0.088 & 55.3 & 0.34 \\
7 & 0.002 & 68.5 & $<0.01$ \\
8 & 0.004 & 71.2 & 0.01 \\
9 & 0.001 & 61.2 & $<0.01$ \\
10 & 0.006 & 71.7 & 0.02 \\
11 & 0.001 & 73.5 & $<0.01$ \\
12 & 0.008 & 75.9 & 0.02 \\
13 & 0.001 & 70.8 & $<0.01$ \\
14 & 0.034 & 70.3 & 0.10 \\
15 & 0.003 & 67.1 & $<0.01$ \\
16 & 0.010 & 84.8 & 0.02 \\
17 & 4.20 & 98.1 & 9.2 \\
18 & 0.019 & 85 & 0.05 \\
21 & 0.055 & 72.7 & 0.16 \\
22 & 0.001 & 56.7 & $<0.01$ \\
23 & 1.12 & 82.4 & 2.9 \\
24 & 0.001 & 78.9 & $<0.01$
\end{tabular}

The presence of $\mathrm{K}-42$ was noticed in those people who had large $\mathrm{Na}-24$ burdens. The amounts present were consistent with estimates from abundance and cross-section data which indicate that there should be about one seventh as many microcuries of $\mathrm{K}-42$ as of $\mathrm{Na}-24$. Employees \#1, \#17, and \#23 were counted several more times at the whole body counter. The $\mathrm{Na}-24$ was observed to disappear with the expected 15 hour half-life. Each of these three men was found to have had some Au-198 produced in fillings in his teeth. In the case of \#17 the gold was in bridge-work that could be removed. This made it possible to count him with the P-32 counter ${ }^{22)}$. After the original report on the counter, the detector was moved to a counting position over the head rather than over the chest in order to reduce interference by other isotopes; 
the presence of radioactive gold fillings would have prevented such measurements. The first count for P-32 was made on \#17 ten days after the accident. The P-32 was easily detected. The counting rate due to the P-32 decreased exponentially with a 14.5 day half-life (i.e., the radioactive decay half-life) rather than the 8 to 10 day half-Iife observed for subjects who recelve P-32 intravenously. This indicater that most of the P-32 being observed was.. formed in the relatively tightly bound phosphorous, probably that in the skull, rather than that more mobile portion in which the intravenously injected P.-32 appears. Thus the calibration of the counter, which was done with intravenously injected subjects, was not applicable; if applied anyway, the calibration would have indicated two to three times as much P-32 as predicted from the activity of the $\mathrm{Na}-24$ present.

\section{$\mathrm{Na}-24$ IN BLOOD}

Two $2 \mathrm{~cm}^{3}$ blood samples each for Imployees $\frac{11}{i} \mathrm{t}$, 17 , and the were counted for $\mathrm{Na}-24$. The first samples were counted on a three inch well crystal scintillation counter. They had coagulated before they could be counted. The second set of samples was treated with heparin to prevent coagulation. They were counted for 30 minutes on a total absorption gamaray spectrometer ${ }^{23)}$. The results of the two counts, corrected for decay from the time of the accident, are given in Table V. The agreement is considered reasonably good.

The activity density of the $\mathrm{Na}-24$ in the whole blood was converted to neutron first collision dose by multiplying by the factor $1.65 \times 10^{5}$ $\mathrm{rad}-\mathrm{cm}^{3} / \mathrm{\mu c}$. This is the ratio of first collision dose to blood activity found in the Oak Ridge burro experiment ${ }^{19)}$. 
If the sodium in the whole body and in the blood are equally irradiated by slow neutrons or if there is rapid equilibration of the sodium throughout all compartments in the body, then this factor should be related to the factor used above with the whole body counter data. The ratio of $\mu \mathrm{c} / \mathrm{kg}$ of $\mathrm{Na}-24$ in the body to $\mu \mathrm{c} / \mathrm{cm}^{3}$ in the blood should equal the ratio of the density of sodium in the body (105 g/70 kg for the standard man ${ }^{24}$ ) to that in the blood $\left.\left(1.91 \times 10^{-3} \mathrm{~g} / \mathrm{cm}^{3} 25\right)\right):\left(1.01 \times 10^{-3} \times 70\right) / 105=1.27$

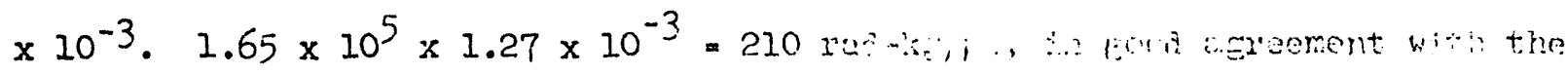

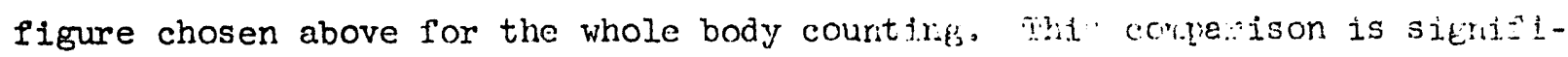
cant because the blood and whole body activities of the buire were determined in different ways. A similar comparison can be made using the data obtained after the critical accident at Los Alamos. The fatally exposed employee was found to have $0.00531 \mu \mathrm{c} / \mathrm{cm}^{3}$ of $\mathrm{Na}-24 \mathrm{l}$ in whole blood and $293 \mu \mathrm{c}$ in his whole body, which weighed $71.5 \mathrm{~kg}^{26)} \cdot(0.00531 \times 71.5) / 293=1.30 \times 10^{-3}$ in good agreement with the above value. This latter value is particularly significant because the neutron dose distribution in the man's body was very non-uniform. The agreement between the two results indicates that the sodium had been able to effectively equilibrate throughout the body.

\section{TABIE V}

$\mathrm{Na}-24$ in Blood

(Two Samples From Each Employee)

\begin{tabular}{|c|c|c|c|}
\hline \multirow{2}{*}{$\frac{\text { Employee }}{\# 1}$} & \multirow{2}{*}{$\begin{array}{c}\mathrm{Na}-24 \\
\mathrm{uc} / \mathrm{cm}^{3} \text { blood } \\
1.5 \times 10^{-4} \\
1.8 \times 10^{-4}\end{array}$} & \multicolumn{2}{|c|}{$\begin{array}{c}\text { Neutron First } \\
\text { Collision Dose } \\
\text { rads } \\
\end{array}$} \\
\hline & & $\begin{array}{l}25 \\
30\end{array}$ & $\begin{array}{l}t 2.5 \\
Z 3.0\end{array}$ \\
\hline$\# 17$ & $\begin{array}{l}8.8 \times 10^{-5} \\
7.3 \times 10^{-5}\end{array}$ & $\begin{array}{l}15 \\
12\end{array}$ & $\begin{array}{l}2.2 \\
Z 1.2\end{array}$ \\
\hline$\# 23$ & $\begin{array}{l}2.0 \times 10^{-5} \\
2.1 \times 10^{-5}\end{array}$ & & $\left\{\begin{array}{l}1.2 \\
\vdots 0.8\end{array}\right.$ \\
\hline
\end{tabular}


Na-24 IN EXCRETA

The first urine samples from Employees \#1, \#17, and \#23 were counted on a three inch well crystal scintillation counter. These measurements were repeated and all later samples were measured on a five inch well crystal scintillation counter ${ }^{27}$ ). Sample size varied from 2 to $500 \mathrm{~cm}^{3}$ and counting time from 5 to 30 minutes depending on the activity of the sample. The results, corrected for decey from the time of the accident, are given in Table VI. The Na-24 activity found in feces was negligible.

\section{TABLE VI}

\section{Na-24 in Urine}

\begin{tabular}{|c|c|c|c|c|}
\hline Employee & Date & $\begin{array}{c}\text { Average } \\
\text { Dis./min-ml }\end{array}$ & Total ml & $\begin{array}{c}\text { Total } \\
\text { Dis./min }\end{array}$ \\
\hline$\# 1$ & $\begin{array}{l}4 / 7 / 62 \\
4 / 8 / 62 \\
4 / 9 / 62 \\
4 / 10 / 62 \\
4 / 11-12 / 62 \\
4 / 12-13 / 62\end{array}$ & $\begin{array}{r}174.1 \\
210.9 \\
229.7 \\
142.0 \\
77.8 \\
135.0\end{array}$ & $\begin{array}{l}1685 \\
3800 \\
4340 \\
2500 \\
4900 \\
4280\end{array}$ & $\begin{array}{l}2.93 \times 10^{5} \\
8.01 \times 10^{5} \\
9.97 \times 10^{5} \\
3.55 \times 10^{5} \\
3.81 \times 10^{5} \\
5.78 \times 10^{5}\end{array}$ \\
\hline$\# 17$ & $\begin{array}{l}4 / 7 / 62 \\
4 / 8 / 62 \\
4 / 9 / 62 \\
4 / 10 / 62 \\
4 / 11-12 / 62 \\
4 / 12-13 / 62\end{array}$ & $\begin{array}{l}339.5 \\
310.7 \\
185.5 \\
120.0 \\
136.8 \\
135.0\end{array}$ & $\begin{array}{r}580 \\
3020 \\
3200 \\
3300 \\
3225 \\
1950\end{array}$ & $\begin{array}{l}1.97 \times 10^{5} \\
9.38 \times 10^{5} \\
5.94 \times 10^{5} \\
3.96 \times 10^{5} \\
4.41 \times 10^{5} \\
2.63 \times 10^{5}\end{array}$ \\
\hline$\# 23$ & $\begin{array}{l}4 / 7 / 62 \\
4 / 8 / 62 \\
4 / 9 / 62 \\
4 / 12-13 / 62\end{array}$ & $\begin{array}{l}66.7 \\
44.3 \\
27.8 \\
40.5\end{array}$ & $\begin{array}{l}1415 \\
3935 \\
3850 \\
3050\end{array}$ & $\begin{array}{l}0.94 \times 10^{5} \\
1.74 \times 10^{5} \\
1.07 \times 10^{5} \\
1.24 \times 10^{5}\end{array}$ \\
\hline
\end{tabular}

\section{$\underline{P-32 \text { IN HAIR }}$}

Samples of hair were taken from Employees \#1, \#17, and \#23 from several locations on their bodies. The P-32 was separated from the hair ${ }^{28)}$ and counted in a low background proportional counter. The sulfur content was determined for several samples by a spectrometric method and found to agree 
with the results of Peterson, et.al. ${ }^{29)}$ so their value, $47.7 \mathrm{mg}$ sulfur per giam of hair, was then assumed for all calculations. The results are listed In Table VII. The time integral of the flux density of neutrons having energies greater than $2.5 \mathrm{Mev}$ and the first collision dose due to these neutrons were calculated using the formula given by Peterson, et. 0.1. Their formula gives factors of $6.44 \times 10^{6}$ neutrons $/ \mathrm{cm}^{2}$ per dis./min-g sultiul she 0.0246 rads per dis./min-g sulfur.

\section{IABLE VII}

\section{$\underline{P-32 \text { in Hair }}$}

\section{Hair Sample}

Employee Type Top of He

\section{\# 1}

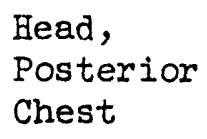

Chest

Pubic

Leg

(Fingernaiz Left Right)

(Toenails)

$\# 17$

\#23
Chest

Pubic

Back

Head

Pubic
0

$33-77$

87

$135-161$
Neutrons Above $2.5 \mathrm{Mev}$

Neutrons $/ \mathrm{cm}^{2}$ Collision Dose

$2.4 \times 10^{9}$ 9.3

$2.9 \times 10^{9}$ 11

$1.8 \times 10^{9}$

$1.5 \times 10^{9}$ 5.6
24

37

11
$43-73$

94

34

0

93
$1.4 \times 10^{9}$

5.2

$7.7 \times 10^{8}$

$9.1 \times 10^{8}$

$4.3 \times 10^{8}$

$3.8 \times 10^{8}$
2.9

3.5

1.6

1.4 


\section{RADIOACTIVITY OF OTHER OBJECTS}

A variety of other objects was collected from the three principals and measured for radioactivity in a five inch well crystal scintillation counter 27 ). Later these same objects were activated with slow neutrons in the large moderator in the same way as in the study of the film badges described above ${ }^{16)}$. The neutron 1 luxes in the large moderator that produced the same activity as In the accident were corrected to allow for the intermediate energy neutron activation during the accident. The effective resonance integrai for the gold in the eye Prames of Employee \#17's glasses was found to be 581 barns (compared to 1300 for thin foils $^{8)}$ ) by the cadmium ratio. Otherwise, the thin foil values were used. The thermal neutron fluxes estimated in this way are listed in Table VIII.

\section{RBE DOSE}

$\mathrm{RBE}$ dose (In rem) is the product of the absorbed dose in rads by an agreed RBE multiplier. Its function is to provide a comon, additive measurewent of all radiations that expresses the radiation protection hazard involved in exposures to the radiations. NBS Handbook $59^{30}$ recommends RBE values which are dependent upon the linear energy transfer to tissue by the charged particles generated by the radiation. These values of $\mathrm{RBE}$ are to be used in assessing hazards due to long continued low level irradiation. The value usually accepted for neutron irradiation is 10 , but this is not applicable for the acute exposures described in this report. Indeed, one of the reasons for the careful analysis of the data provided by such accidents is to provide RBE's that might be suitable. For this reason none of the doses given in this report has been converted to an RBE dose. For purposes of administrative recording of whole body radiation exposures 
TABLE VIII

Radioactivity of Other Objects

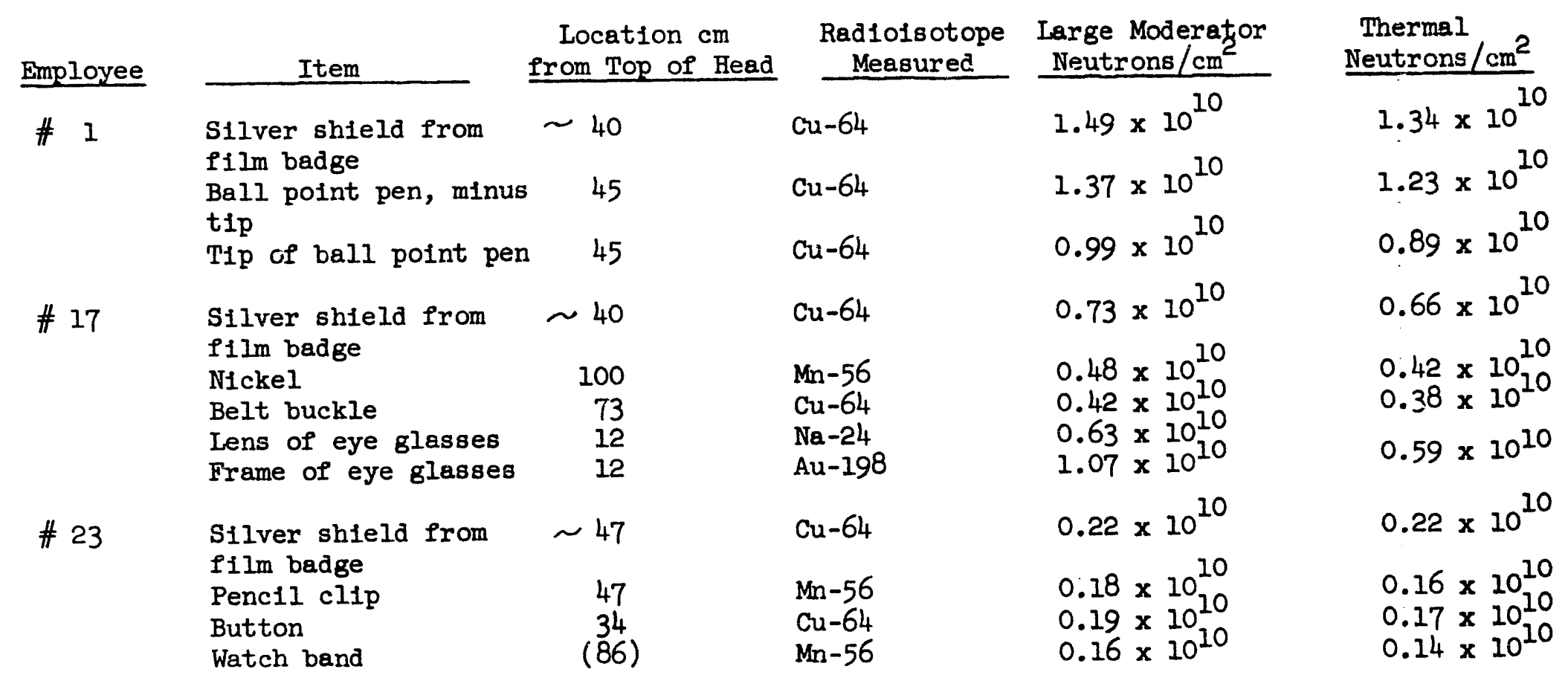


of the employees involved an RBE factor of 2 for acute neutron exposure was assumed. This is largely based on extrapolation from experimental animal exposures and data from previous accidental exposures of humans ${ }^{19)}$. The doses to the eyes were recorded with an assumed RBE of $10^{31}$.

\section{CONCLUSIONS AND SUMMARY}

Our primary sources of information concerning the exposure of individuals during the accident are their personnel dosimeters for the gamma rays and the whole body counts and blood activation for the neutrons. The dosimeters constitute practically point detectors. The backscattering for gamma rays is small so the dosimeters indicate the first collision photon dose where they were worn. The activation of $\mathrm{Na}-24$ takes place throughout the body. The experiments performed to relate $\mathrm{Na}-24$ activation to neutron dose, however, have related the activation to the first collision dose. Consequently, these primary sources give us information on the first collision dose. It has been customary to report first collision doses in accidents such as the present one in the belief that greater complexity would hinder rather than help correlation of observed biological effects with physical dose measurements.

Employees \#I and \#I7 were close enough to the critical vessel that the actual absorbed dose must have been fairly non-uniform within their bodies. The relation of Na-24 activation to first collision dose may not, therefore, be quite the same as in the calibration experiments. The relationship is even more complicated by the fact that we do not know the exact course of events following the first critical excursion. During this period the men were moving rapidy and their position and orfentation relative to the critical vessel were constantly changing. We do not know if there were 
any other critical excursions during this period or whether they recelved practically all their dose during the first one. The only indication we have that these subsequent motions were not very important is the value of the ratio of the gama ray to the neutron dose. This ratio was between 2 and 3 for the two men close to the critlcal vessel. Th1s is in good agreement with values observed in similar circumstances 6 ). Their motions and the possible later excursions would affect their personnel dosimeter readings even more than the Na-24 activation because of the changing shielding of the dosimeters by the body. The fact that they do not appear to have had a substantial effect on the ratio suggests that most of the dose came during one critical excursion while they were nearly stationary.

The doses determined from sulfur activation in hair were about one half those obtained from Na-24 activation. They should, of course, be lower because they are the doses for only those neutrons above $2.5 \mathrm{Mev}$. The threshold detector, Table I, would indicate that only 20 percent of the dose should come from such neutrons. The application of the latter data are suspect because, as already discussed, the detector may not have been exposed to exactly the same spectrum as the people. On the other hand, some of the difference may be due to a difference in the relation between first collision dose and Na-24 activation in the calibration experiments and in the present accident because of greater non-uniformity of the dose distribution during the accident. The neutrons/ $\mathrm{cm}^{2}$ detected by sulfur activation can also be compared with the number of thermal neutrons. There are several measurements of the two on exposed people that are for nearly the same parts of the body. A ratio of neutrons $/ \mathrm{cm}^{2}$ above the sulfur threshold to thermal neutrons $/ \mathrm{cm}^{2}$ of about 0.2 was obtained where such 
measurements were made. The threshold detector gave 0.3. Probably this is as close agreement as we can expect. The scattering and ausorbing materials in a human body are enough different from those near the detector to produce this much difference in the thermal flux density. (It will be noted that these ratios differ by just the factor of 1.5 by which the calibration of the threshold detector was changed to allow for the energy at which the calibration was made. Some of the difference may be due to error in this factor. The calibration was performed at $4.2 \mathrm{Mev}$. The $S(n, p)$ cross section has a sharp maximum at this energy. A small error in energy would have resulted in decreasing the factor.)

It appears that there may be some uncertainty in the doses from the Na-24 activation, but that it is probably not very great. Employee \#I received the highest exposure. The first collision doses were 23-30 rads from fast neutrons and 63 roentgens in the central region of his body. The dose due to thermal neutrons was negligible in comparison. The P-32 measurements in hair suggest a variation by a factor of at least two for the doses in different parts of the body. This is compatible with varlation as the inverse square of the distance from the center of the critical vessel. The neutron dose to the eyes is considered to be of importance in an exposure such as this because of the possibility of cataract formation. Inverse square variation suggests a dose of $42-54$ rads of neutrons for his eyes.

Employee \#17 recelved the next highest exposure. They were 9-12 rads from neutrons and 23 roentgens in the central region of the body. These doses are related to those recelved by \#I by the Inverse square of the distance from the center of the critical vessel. By the inverse square law the neutron dose to his eyes must have been $11-14$ rads. 
Employee \#23 received about 3 rads from neutrons and 13 roentgens and these must have been pretty uniform over his body. Employees \#6 and $\# 21$ each received about 1 roentgen and 0.34 and 0.16 rads from neutrons, respectively. The rest of the people in the $234-5$ Building at the time of the accident recelved considerably less exposiure. The doses they did receive can be taken to be those given by their personnel dosimeters, Table II, and their whole body counts, Table IV. 


\section{REFERENCES}

1. Wilson, R. H.,A Method for Immediate Detection of High Ievel Neutron Exposure by Measurement of Sodiun-24 in Humans, HW-73891. June, 1962.

2. Hurst, G. S., J. A. Harter, P. N. Hensley, W. A. Mills, M. Slater, and P. W. Reinhardt, "Techniques of Measuring Neutron Spectra with Threshold Detectors - Tissue Dose Determinations", Rev. Sc1. Inst. 27 153-156 (1956).

3. Sayeg, J.A., D. G..Ott, and P. S. Harris, Dosimetry for the Iittle Eva Critical Assembly, IA-2468. November, 1960.

4. Hurst, G. S., R. H. Ritchie, and L. C. Emerson, "Accidental Radiation Excursion at the Oak Ridge Y-12 Plant - III", Health Physics 2 121-133 (1959).

5. Hurst, G. S., R. H. Ritchie, F. W. Sanders, P. W. Reinhardt, J. A. Auxier, E. B. Wagner, A. D. Callihan, and K. Z. Morgan, "Dosimetric Investigation of the Yugoslav Radiation Accident", Health Physics 5 179-202 (1961).

6. Ritchie, R. H., H. B. Eldridge, and V. E. Anderson, "Calculation of the Radiation Yield Irom Fission Assemblies and Comparison with Experiments", in Selected Topics in Radiation Dosimetry, pp 651-666. International Atomic Energy Agency, Vienna, Austria, 1961.

7. Bramson, P. E., Calibration of the Eurst Neutron Threshold Dosimeter System at Hanford, HW-66727. December, 1960.

8. Hughes, D. J., Pile Neutron Research, p 139. Cambridge, Mass.: AddisonWesley, 1953.

9. Wilson, R. H., V. M. Milligan, C. M. Unruh and H. V. Larson, Gamma Calibration and Evaluation Techniques for Hanford Beta-Gamma Film Badge Dosimeters, HW-71702. September, 1960.

10. Iarson, H. V., and W. C. Roesch, Gamma Dose Measurement with Hanford Film Badges, HW-32516. July, 1954.

11. Smith, R. J., Thermal and Fast Neutron Effects on Dosimeter FiIms, NDL-TR-13. 1961 .

12. Swanberg, F., A Personnel Film Badge Neutron Dosimeter, HW-56827. July 1958.

13. Berlman, I. B., H. F. Lucas, and H. A. May, "The Determination of Photographic Film Exposure by Neutron Activation of Ag-107", Rev. Sci. Inst. 24396 (1953).

14. Redaie, J.S., Determination of F1Im Exposure by Neutron Activation of the Reduced Silver, HW-30606. January, 1954. 
15. DePangher, J., L. L. Nichols, and R. A. Kent, Characteristfics of a Large Neutron Moderator for Activation Studies, HW-73913. 1962.

16. DePangher, J.,, R. A. Kent, and L. L. Nichols, Application of the Large Moderator to Dosimetry Studies of the Recuplex Incldent, HW-73914. 1962.

17. Wilson, R. H., and H. V. Larson, F1lm Capabilities for High Level Dose Evaluation, HW-71133. September, 1961 .

18. Roesch, W. C., R. C. McCall, and H. E. Palmer, Hanford Whole Body Counter 1959 Activities, HW-67045. December, 1960.

19. Accidental Radiation Excursion at the Y-12 Plant, Y-1234. June, 1958.

20. Harris, P. S., "Acute Radiation Death Resulting From an Accidental Nuclear Excursion. Section VI Dosimetric Calculations", Journal of Occupational Medicine, Special Supplement, March, 1961.

21. Hurst, G. S., and R. H. Ritchie (ed.), Radiation Accidents: Dosimetric Aspects of Neutron and Gamma-Ray Exposures, ORNL-2748, Part A. November, 1959 .

22. Palmer, H. E., "Detection of P-32 in Vivo", Radiology 78115 (1962).

23. Perkins, R. W., J. M. Nielsen, and R. N. Diebel, "Total Absorption GammaRay Spectrometers Utilizing Anticoincidence Shielding", Rev. Sci. Inst. 31 1344-1349 (1960).

24. "Recommendations of the International Commission on Radiological Protection", British Journal Radiol. Supplement \#6, 1955.

25. Spector, W. S., Handbook of Blological Data, Philadelphia: Saunders, 1956.

26. Langham, W. H., "Acute Radiation Death Resulting from an Accidental Nuclear Excursion. Section V. Special Studies", Journal of Occupational Medicine, Special Supplement. March, 1961.

27. Perkins, R. W., The Response of Various Detector Sample Arrangements for Gamma-Ray Spectrometric Measurements, HW-68525. April, 1961.

28. Silker, W. B., "Radiochemlcal Determination of Phosphorus-32", Analytical Chemistry 28 1782-1783 (1956).

29. Peterson, D. F., F. E. M1tchell, and W. H. Langham, "Estimation of Fast Neutron Doses in Man by $\mathrm{S} 32$ ( $n, p) \mathrm{P} 32$ Reaction in Body Hair", Health Physics 6 1-5 (1961).

30. Permissible Dose from External Sources of Ionizing Radiation, NBS Handbook 59, Superintendent of Documents, Washington, D.C., 1954.

31. Personal Communication, V. P. Bond to A. R. Keene, May 9, 1962. 

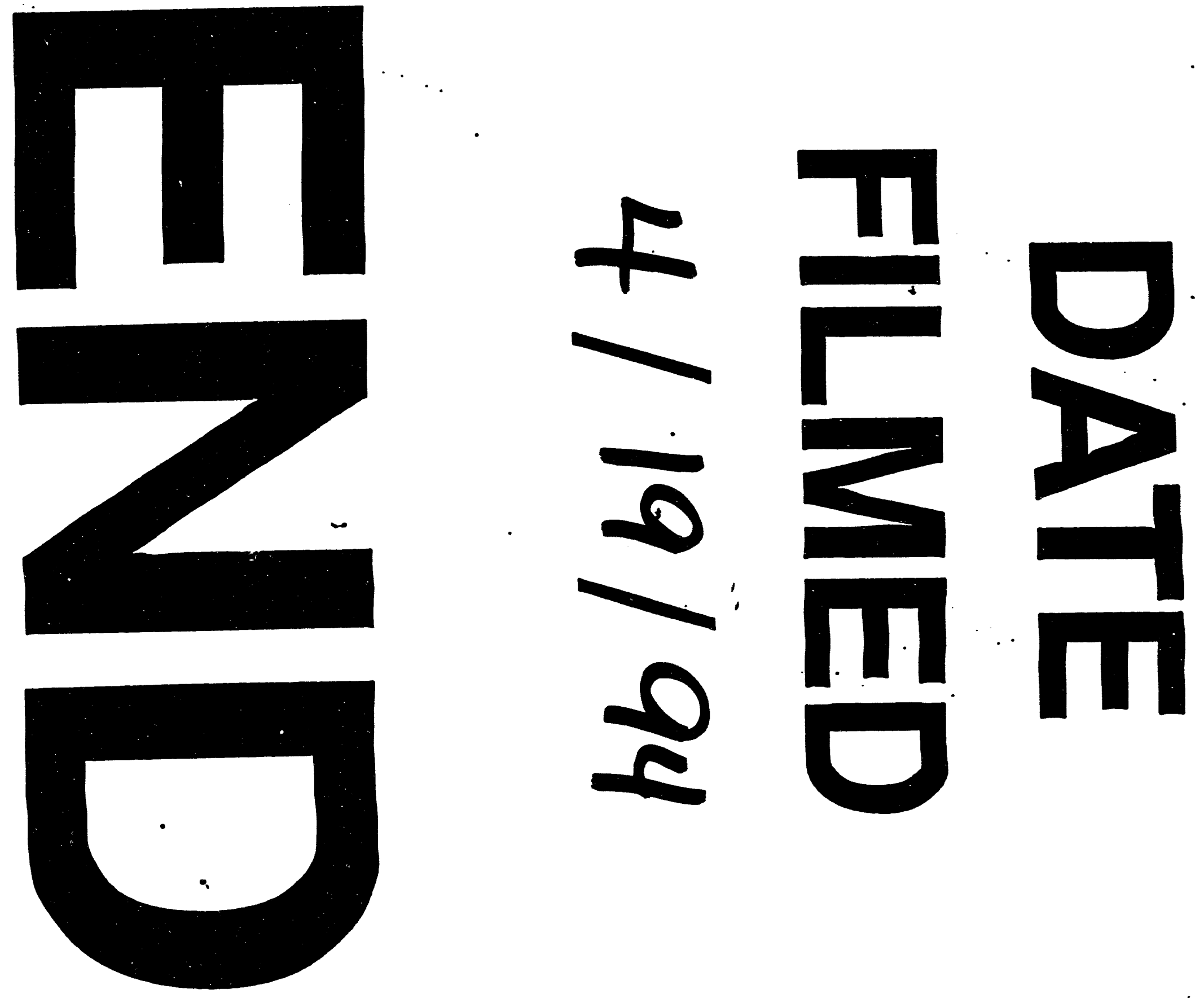

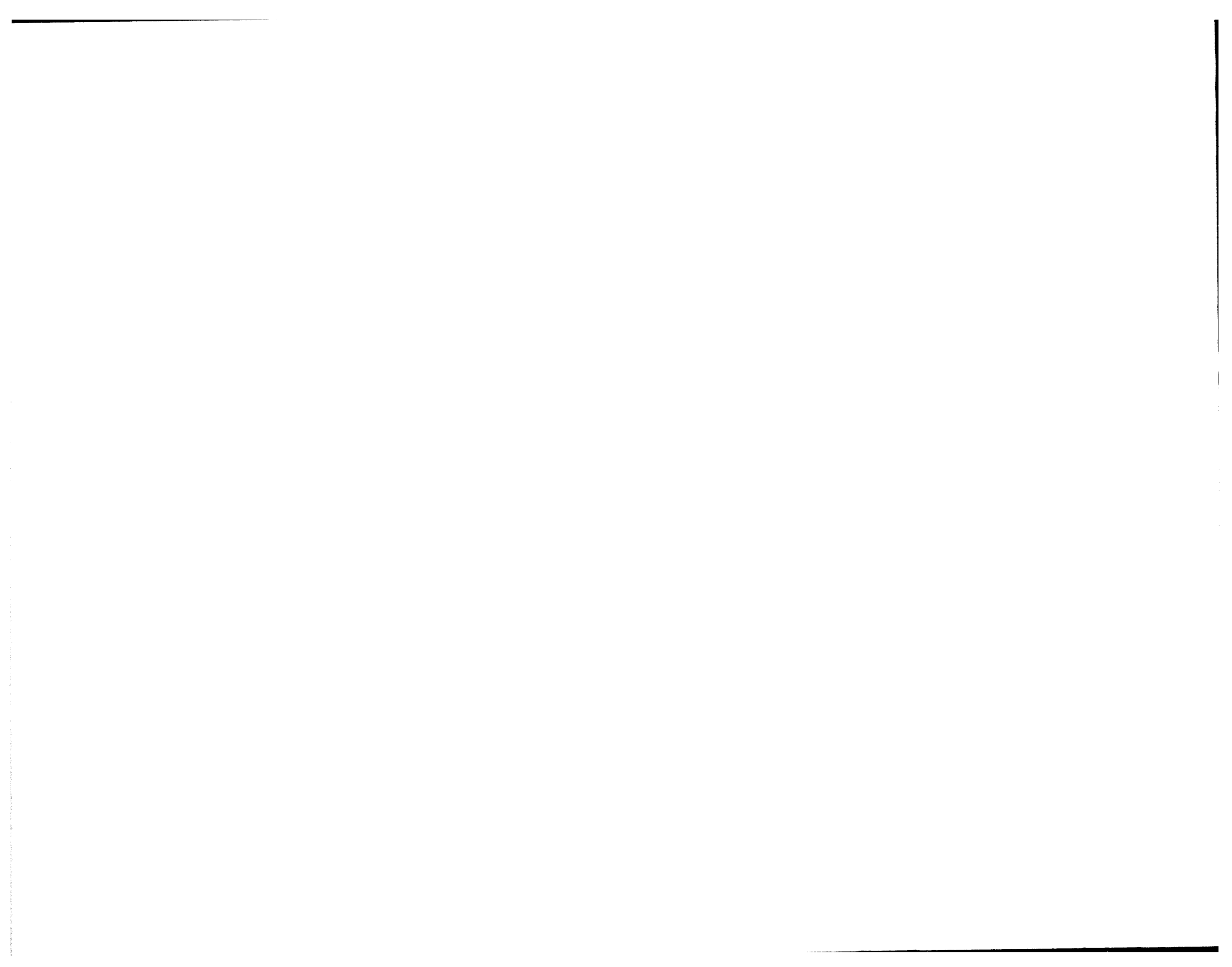

I 